\title{
Territorial analysis of Aedes aegypti distribution in two Colombian cities: a chorematic and ecosystem approach
}

\author{
Análisis territorial de la distribución de \\ Aedes aegypti en dos ciudades de Colombia: \\ aproximación desde la coremática y el enfoque \\ ecosistémico
}

\begin{abstract}
Análise territorial da distribuição do Aedes aegypti em duas cidades da Colômbia: aproximação desde a coremática e a abordagem ecossistêmica
\end{abstract}

\author{
Mauricio Fuentes-Vallejo 1 \\ Diana Rocío Higuera-Mendieta 1 \\ Tatiana García-Betancourt 1 \\ Lucas Andrés Alcalá-Espinosa 1 \\ Diana García-Sánchez 1 \\ David Alejandro Munévar-Cagigas 1 \\ Helena Luisa Brochero 2 \\ Catalina González-Uribe 1 \\ Juliana Quintero ${ }^{1}$
}

\footnotetext{
${ }^{1}$ Fundación Santa Fe de Bogotá, Bogotá, Colombia.

2 Facultad de Ciencias Agrarias, Universidad Nacional de Colombia Bogotá, Colombia.

Correspondence M. Fuentes-Vallejo Fundación Santa Fe de Bogotá.

KR $7 B 12390$, Bogotál Bogotá DC-110111,

Colombia.

mauricio.fuentes@fsfb.org.co
}

\begin{abstract}
A territorial analysis of Aedes aegypti density was conducted in two Colombian cities using an ecosystem and chorematic approach. Entomological and behavioral data (by cluster) and information on the urban context were used to analyze the relationship between territorial structures and dynamics and vector density. The results were represented in graphic (chorematic) models. Arauca showed higher vector density than Armenia. Higher density was related to unplanned urbanization, flood-prone areas, low socioeconomic strata, household water tanks, higher temperature, and recall of control measures for adult mosquitos. Zones with low density indices coincided with diverse socioeconomic, ecological, and behavioral conditions. The study found a relationship between territorial structures and dynamics and vector density in both Arauca and Armenia, where the interaction between ecological and social systems shape areas with high and low A. aegypti density.
\end{abstract}

Aedes; Dengue; Medical Geography; Urban Zones; Social Conditions

\section{Resumen}

Se realizó un análisis territorial de la densidad de Aedes aegypti en dos ciudades de Colombia desde un enfoque ecosistémico y la coremática. A partir de información entomológica y comportamental (por conglomerados) e información del contexto urbano, se indagó la relación de estructuras y dinámicas del territorio con la densidad vectorial. Se representaron los resultados con modelos gráficos (coremática). Se identificó mayor densidad vectorial en Arauca que en Armenia. Mayores densidades se relacionaron con urbanización no planeada, zonas de inundación, estratos socioeconómicos bajos, tanques bajos (alberca), mayor temperatura y reporte de acciones hacia los mosquitos adultos. Zonas de densidades bajas coincidieron con diversas condiciones socioeconómicas, ecológicas y comportamentales. Se encontró relación de las estructuras y dinámicas del territorio con la densidad vectorial para Arauca y Armenia, donde la interacción entre sistemas ecológicos y sociales configuran zonas particulares de alta y baja densidad de A. aegypti.

Aedes; Dengue; Geografía Médica; Zonas Urbanas; Condiciones Sociales 


\section{Introduction}

Dengue is an emerging and reemerging tropical disease that causes morbidity and mortality in Colombia, especially in urban areas below 1,800 meters above sea level (masl) 1 . Occurrence of the disease requires the etiological agent (dengue virus), a biological vector (Aedes aegypti L Diptera: Culicidae), and a susceptible human. Since the mosquito vector's habits are associated with the domestic environment 2 , a comprehensive analysis of urban space is essential for understanding dengue epidemiology in endemic areas.

The academic community, government, and international agencies have produced integrated and holistic approaches in attempts to understand dengue's complexity $3,4,5$, recognize its multiple dimensions, and thus propose sustainable and consistent interventions for the specific contexts. Such approaches (e.g., the ecosystem approach) assume participation by various fields, including geography, which is both pertinent and necessary when studying geographic space.

The appropriation of geographic space, especially the planet's rapid urbanization, produces profound transformations in ecosystems ${ }^{6}$. Geographic space is increasingly artificial, and nature is transformed by humans at unequal rates, according to the relations between societies, their available technical means, and the space in which they develop. Thus, geographic space is defined as "an indivisible, solidary, and contradictory set of systems of objects and systems of actions, not considered separately, rather as a single context in which history unfolds" 7 (p. 54).

Meanwhile, territory (as an analytical category for studying geographic space) is defined as the relations (political, identity, and affective) or dynamics established between subjects and/ or collective groups in the space they inhabit, resulting in the appropriation of a portion of the space, which is conceived as a territory 8 .

In this sense, a better understanding of urbanization's underlying historical and territorial processes allows identifying specificities of the context, which contributes elements for the comprehensive control and prevention of dengue on the urban scale.

We used choremes to graphically depict and understand the territorial dynamics in a given geographic space. This involves an analytical process which begins by viewing the relationship between territory and a given phenomenon $(A$. aegypti density) as a social construct in which one identifies and represents socio-territorial logics that intervene in the process of appropriation ${ }^{9}$. While a map is also a representation of geographic space that "shows" given a reality, the choreme seeks to understand it 10 .

This study's objective was to conduct a territorial analysis of dengue, specifically the density of the A. aegypti vector, in two cities of Colombia (Arauca and Armenia) from an ecosystem approach, applying the chorematic conceptual and methodological framework.

\section{Materials and methods}

\section{Study area}

The study was done in two dengue-endemic municipalities (counties). Arauca has had endemic/epidemic dengue transmission and a total of 7,992 cases from 1999 to 2010, reporting the second largest number of cases in its region (Orinoquía). Armenia reported 24,008 cases during the same period (the largest number of cases in the Central-Western region of Colombia) and also displayed an endemic-epidemic pattern of dengue transmission 1 .

The city of Arauca is located in the Northeast of Colombia (705'05”N/7045'30”W) along the Río Arauca, which marks the border with the Bolivarian Republic of Venezuela. The landscape is typically flat, with a mean altitude of 124 masl and well-defined a rainy season from April to October and dry season from November to March 11. This pattern is expressed in a water system consisting of the principal river basin (Río Arauca) and smaller drainage systems and bodies of water that fluctuate, with partial floods during the rainy season. The urban area measures approximately $19.9 \mathrm{~km}^{2}$, with 85,994 inhabitants and an urban population density of 4,321 inhabitants/ $\mathrm{km}^{2}$. The city's main environmental protection area (with bodies of water) divides the urban area, with more formal urbanization to the north (higher and more consolidated population density, formal and informal commerce, supply of institutional services, and residential areas). The area south of the environmental protection area is characterized by scattered urbanization with isolated residential areas in various degrees of consolidation, besides the airport, informal commerce, and land for the city's expansion.

Armenia is located in central Colombia (4'32'15”N/7540'20”W). The landscape features foothills with fans that originated from volcanic activity in Colombia's central cordillera. This landscape was shaped by natural drainage systems that produced valleys up to 20 meters deep and 50 to 1,000 meters wide 12 . The altitude ranges from 1,600masl in the far northeastern part of the city to 1,300 masl in the southwestern part. Cli- 
matic conditions vary between the rainy seasons (April-May, October-December) and dry seasons (January-March, June-September) 11. The urban area of Armenia measures 31.8km², with 293,605 inhabitants and an urban population density of 9,233 inhabitants $/ \mathrm{km}^{2}$. The northeastern part of the city has predominantly higher income strata and formal commerce. The city's historical center and area of influence are characterized by the presence of formal and informal commerce and government agencies, as well as a middle- and low-income population. The southwestern part of the city is divided by deep, wide valleys with areas of urban expansion, and predominantly middle to very low-income residential areas.

\section{Data sources}

The study used primary and secondary qualitative and quantitative data sources (Table 1).

The primary sources refer to information collected directly in the field, using a randomized cluster design. The sample size (20 clusters per city) aimed at future evaluation of dengue vector control strategies, as performed elsewhere in Latin America 13 and Asia 14. Entomological information and knowledge, attitudes, and practices (KAP) data were used from the 20 clusters per city, which included approximately 100 contiguous households per cluster (Arauca $n=1,926$, Armenia $n=1,936)$. Other primary sources included interviews with different key groups as well as field observations. This information was collected during the dry season (December 2012 to March 2013) in both cities using mobile devices that allowed recording the geographic coordinates of the households and public spaces in each cluster.

The secondary sources included the available epidemiological information from the two cities' public health agencies, a literature review on their social, economic, and political context, and institutional documents and maps on territorial planning.

\section{Analysis}

Vector density was measured in each cluster using the Pupae per Person Index (PPI), defined as the number of A. aegypti pupae in relation to the number of inhabitants in each cluster, and the Breteau Index (BI), defined as the number of containers with $A$. aegypti pupae per hundred households inspected 15 . The two indices were classified for each city as "high" and "low", using the median as the cutoff point (Table 2). Other biological, socioeconomic, and KAP variables were classified for each city as "high" (above the 66th percentile), "medium" (from the 33rd to the 66th percentile, and "low" (below the 33rd percentile) (Table 1). The analysis and development of the thematic mapping for variables used ArcGIS 10.0 (ESRI Inc., Redlands, USA).

We adopted chorematic modeling, originally developed by Roger Brunet 16, as a conceptual and methodological tool used previously on multiple topics 9 , including analysis of the configuration of Colombia's territory 17 and the territorial dynamics of dengue in Brazil 18. Importantly, these graphic representations (or models) highlight the territorial structures and processes more than the element's exact location, a function covered adequately by conventional mapping.

We began by conducting a graphic abstraction of the study area's boundaries (the urban areas of Arauca and Armenia) which was later used to develop individual choremes for different territorial structures and dynamics through such conventional variables as: physical environment (temperature, humidity, altitude, hydrology), urban planning (land use and urban function), knowledge, attitudes, and practices related to dengue and the mosquito, among others. Figure 1 illustrates how the graphic abstraction was done and the use of the above-mentioned conventions in the case of Armenia. Finally, these individual choremes were compared to the distribution of $A$. aegypti density in each cluster to produce a summary choreme, representing the territorial dynamics of dengue vector density in Arauca and Armenia (Figures 2 and 3).

The study was approved by the Ethics Research Committee of Fundación Santa Fe de Bogotá, as recorded in the minutes of the meeting held on November 19, 2012, and informed consent was obtained for all the surveys and interviews.

\section{Results}

Higher entomological indices were observed in Arauca $(\mathrm{PPI}=0.99 ; \mathrm{BI}=8.15)$ than in Armenia $(\mathrm{PPI}=0.22 ; \mathrm{BI}=5.68)$. The indices differed by cluster, with PPI ranging from 0.09 to 3.11 in Arauca and from 0 to 0.95 in Armenia. Reported BI values ranged from 1.15 to 16.00 and from 0 to 14.74 in Arauca and Armenia, respectively (Table 2).

For clusters 6 and 10 in Arauca and 15 and 19 in Armenia, Table 2 shows high BI and low PPI, indicating potential risk since there were many containers with pupae per cluster, although the number of pupae was not that high in relation to the population. Clusters 4 and 11 in Arauca and 11 in Armenia showed low BI and high PPI, 
Table 1

Primary and secondary sources used in the elaboration of urban-scale choremes. Arauca and Armenia, Colombia.

\begin{tabular}{|c|c|c|}
\hline Group of variables & Variables & Source \\
\hline \multirow[t]{2}{*}{ Pupa indices (households and public spaces) } & Pupae per Person Index * & Primary \\
\hline & Breteau Index for Pupae * & \\
\hline \multirow[t]{7}{*}{ Biological (entomological and ecological) } & Mean outdoor temperature & Primary \\
\hline & Mean relative humidity & \\
\hline & Type of water in inspected containers (tap water, rainwater, or mixed) ** & \\
\hline & Number of most pupa-productive containers inspected (water tanks) ** & \\
\hline & Altitude & Secondary \\
\hline & Bodies of water (lagoons, wetlands, oxbow lakes) & \\
\hline & Natural and artificial drainage systems (rivers, canals) & \\
\hline \multirow[t]{7}{*}{ Socioeconomic and urban dynamics } & Healthcare coverage (subsidized, contributive, special) ** & Primary \\
\hline & Socioeconomic stratum (1 to 6$)^{\star \star}$ & \\
\hline & Stayed in the same place or migrated after 1999 earthquake in Armenia ** & \\
\hline & Central urban areas (historical city center, business districts, business corridors) & Secondary \\
\hline & Main roadways & \\
\hline & $\begin{array}{l}\text { Land use (residential, commercial, urban renewal or upgrading, urban expansion, } \\
\text { environmental protection) }\end{array}$ & \\
\hline & Population's mobility (intra-urban, interurban, and international) & \\
\hline \multirow[t]{5}{*}{ Knowledge, attitudes, and practices (KAP) } & Knowledge on dengue and vector ** & Primary \\
\hline & Recall of visits by vector control program in previous year ** & \\
\hline & $\begin{array}{l}\text { Perception of responsibility in dengue prevention (government, health sector, community, } \\
\qquad \text { or individuals themselves) }\end{array}$ & \\
\hline & Measures to reduce inconvenience of mosquitos according to stage (immature or adult) ** & \\
\hline & Water storage in household ** & \\
\hline \multirow[t]{6}{*}{ Historical and urban planning context } & Semi-structured interviews with community leaders, the community, and decision-makers & Primary \\
\hline & (Arauca and Armenia) & \\
\hline & Field observations ( 3 visits per city) & \\
\hline & Dynamics of forced displacement in Arauca & Secondary \\
\hline & Reconstruction of Armenia after 1999 earthquake & \\
\hline & Development Plan, Master Plan, and cartography (Arauca and Armenia) & \\
\hline
\end{tabular}

* Variables classified as high or low, using the median as the cutoff point for mapping;

** Variables classified as high (above the 66th percentile), medium (between 33rd and 66th percentiles), and low (below the 33rd percentile) for mapping

indicating a focused risk of a high number of pupae in a few containers per cluster. In the other clusters, the high and low BI and PPI values coincided. Figures 2 and 3 show the clusters' location in each city.

\section{Vector density in Arauca and its relationship to the territory's ecological and social structures}

The following is a description of the different zones identified in Arauca, according to vector density and the territory's ecological and social structures.

\section{- Peripheral corridor with high Aedes aegypti density}

Following the path of the Rio Arauca (Figure 2), one identifies a peripheral corridor with 5 clusters with high vector density indices, sharing characteristics such as predominantly very low income, location in flood-prone areas, informal border activity, fully improved neighborhoods, bodies of water, and higher mean temperature $\left(31.1^{\circ} \mathrm{C}\right)$ compared to the rest of the city $\left(28.7^{\circ} \mathrm{C}\right)$. This corridor also displays behaviors associated with vector productivity, especially storing water in the households ( 4 of the 5 clusters reported household water storage rates greater than $82 \%$ ), and these clusters had the highest recall rates 
Entomological indices by cluster in Arauca and Armenia, Colombia.

\begin{tabular}{|c|c|c|c|c|c|c|c|c|c|c|}
\hline \multirow{3}{*}{$\begin{array}{l}\text { Cluster } \\
1\end{array}$} & \multicolumn{5}{|c|}{ Arauca } & \multicolumn{5}{|c|}{ Armenia } \\
\hline & \multirow{2}{*}{$\begin{array}{c}\text { Households } \\
96\end{array}$} & \multicolumn{2}{|c|}{$\mathrm{BI}$ * } & \multicolumn{2}{|c|}{$\mathrm{PPI}$ * } & \multirow{2}{*}{$\begin{array}{c}\text { Households } \\
96\end{array}$} & \multicolumn{2}{|c|}{$\mathrm{BI}$ * } & \multicolumn{2}{|c|}{$\mathrm{PPI}$ * } \\
\hline & & 11.46 & High & 1.50 & High & & 0.00 & N/A & 0.00 & N/A \\
\hline 2 & 94 & 5.32 & Low & 0.22 & Low & 95 & 0.00 & N/A & 0.00 & $\mathrm{~N} / \mathrm{A}$ \\
\hline 3 & 94 & 11.70 & High & 1.24 & High & 91 & 3.30 & Low & 0.07 & Low \\
\hline 4 & 94 & 3.19 & Low & 1.23 & High & 94 & 0.00 & N/A & 0.00 & $\mathrm{~N} / \mathrm{A}$ \\
\hline 5 & 96 & 9.38 & High & 1.84 & High & 93 & 4.30 & Low & 0.14 & Low \\
\hline 6 & 96 & 8.33 & High & 0.39 & Low & 98 & 9.18 & High & 0.65 & High \\
\hline 7 & 97 & 11.34 & High & 0.83 & High & 98 & 4.08 & Low & 0.04 & Low \\
\hline 8 & 97 & 3.09 & Low & 0.14 & Low & 99 & 5.05 & Low & 0.13 & Low \\
\hline 9 & 98 & 12.24 & High & 2.08 & High & 100 & 0.00 & N/A & 0.00 & $\mathrm{~N} / \mathrm{A}$ \\
\hline 10 & 97 & 9.28 & High & 0.78 & Low & 97 & 4.12 & Low & 0.04 & Low \\
\hline 11 & 99 & 7.07 & Low & 3.11 & High & 100 & 6.00 & Low & 0.41 & High \\
\hline 12 & 100 & 16.00 & High & 1.30 & High & 99 & 8.08 & High & 0.67 & High \\
\hline 13 & 100 & 11.00 & High & 2.12 & High & 96 & 3.13 & Low & 0.03 & Low \\
\hline 14 & 93 & 15.05 & High & 1.13 & High & 99 & 6.06 & Low & 0.13 & Low \\
\hline 15 & 98 & 6.12 & Low & 0.16 & Low & 99 & 9.09 & High & 0.13 & Low \\
\hline 16 & 87 & 1.15 & Low & 0.09 & Low & 96 & 10.42 & High & 0.19 & High \\
\hline 17 & 93 & 5.38 & Low & 0.18 & Low & 93 & 8.60 & High & 0.28 & High \\
\hline 18 & 97 & 2.06 & Low & 0.10 & Low & 101 & 10.89 & High & 0.95 & High \\
\hline 19 & 100 & 6.00 & Low & 0.59 & Low & 97 & 6.19 & High & 0.09 & Low \\
\hline 20 & 100 & 7.00 & Low & 0.55 & Low & 95 & 14.74 & High & 0.27 & High \\
\hline Total & 1.926 & 8.15 & & 0.99 & & 1.936 & 5.68 & & 0.22 & \\
\hline
\end{tabular}

BI: Breteau index for pupae; PPI: Pupae per Person index.

* Classified as high or low, using the median as the cutoff point for mapping.

in the city for community actions against adult mosquitoes.

In the city as a whole, $86 \%$ of the population felt that the responsibility for dengue is individual, while this peripheral corridor showed the highest percentages of people ( $37 \%$ to $47 \%$ ) assigning responsibility for dengue prevention to the government (Office of the Mayor, Health Secretariat). The study also found low and medium recall $(36 \% ; 66 \%)$ of visits from the vector control program in the previous year.

\section{- Central zone with high Aedes aegypti density}

Another 6 clusters located in the central part of the city also reported high vector density. They have very low to middle-income strata and high rates of household water storage, but unlike the clusters in the peripheral corridor, they reported medium to high recall of visits from the vector control program in the previous year $(60 \%$ to $74 \%)$.

\section{- Zone with heterogeneous conditions and} mixed Aedes aegypti density (low to high)

We identified another group of 6 clusters where half had high entomological indices and the other half had low indices, located between the central part of the city and the Rio Arauca (Figure 2). This group shares a diversity of social and ecological conditions, with no obvious specific pattern.

\section{- Zone with heterogeneous conditions and low Aedes aegypti density}

Towards the south of the environmental protection area, where the population is grouped in scattered urban settlements, 5 clusters were identified with low indices. Three had predominantly very low-income households, another one was low-income, and the last one had uppermiddle class households. Following the trend, high indoor water storage rates were reported in two clusters, medium in another two, and low in the cluster with predominantly very low-income 
Figure 1

Example of development of choremes, based on the city of Armenia, Colombia.

Individual choremes of territorial structures and dynamics
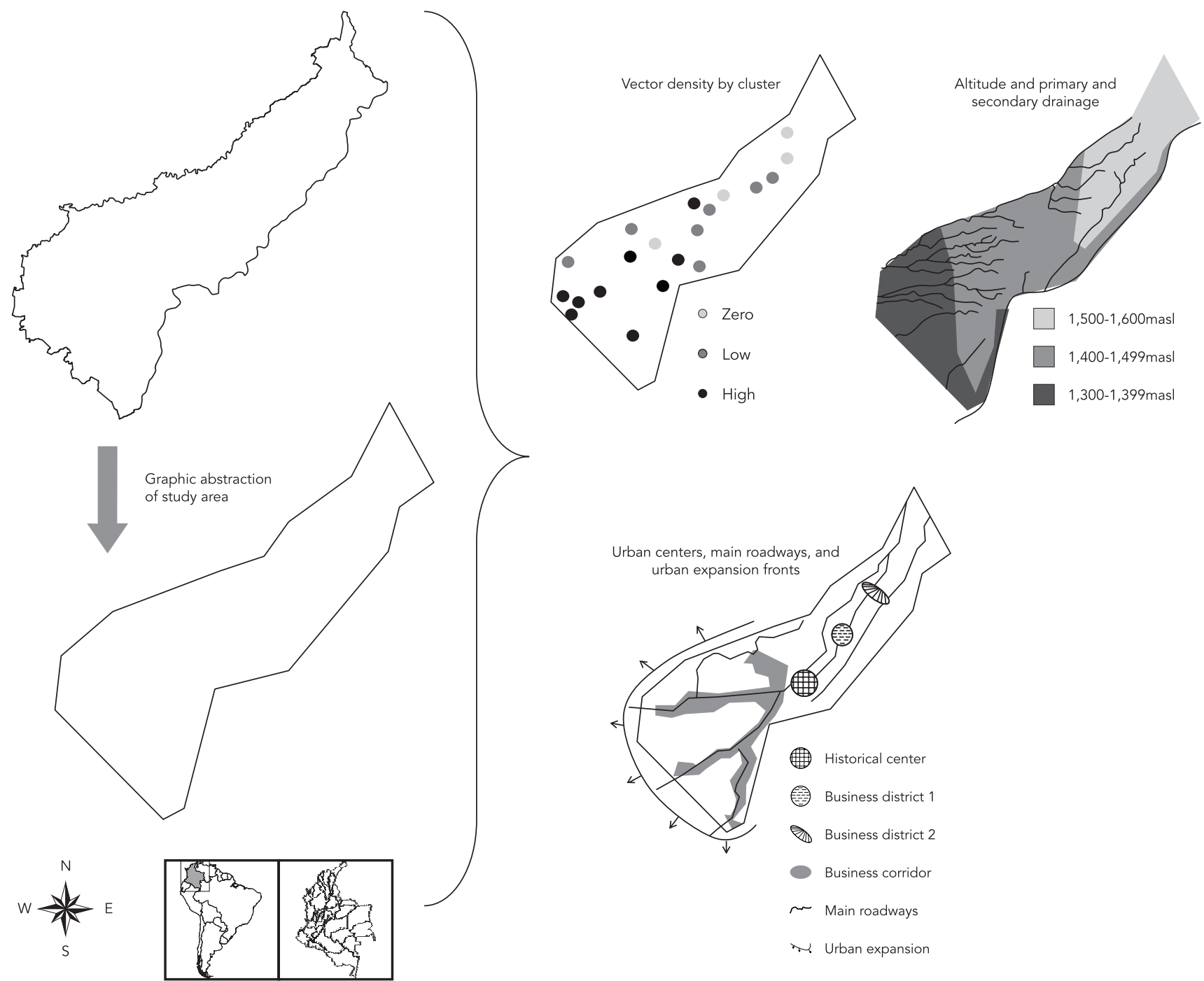
urban expansion fronts

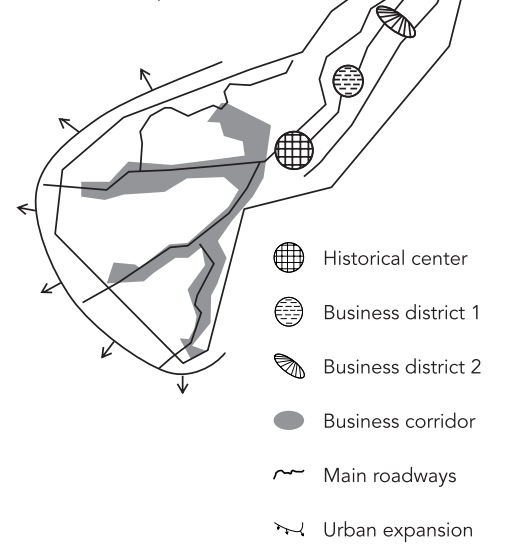

$\begin{array}{llll}0 & 1 & 2 & 4 \mathrm{~km}\end{array}$ 
Figure 2

Summary choreme for territorial dynamics of the Aedes aegypti dengue vector in Arauca, Colombia.

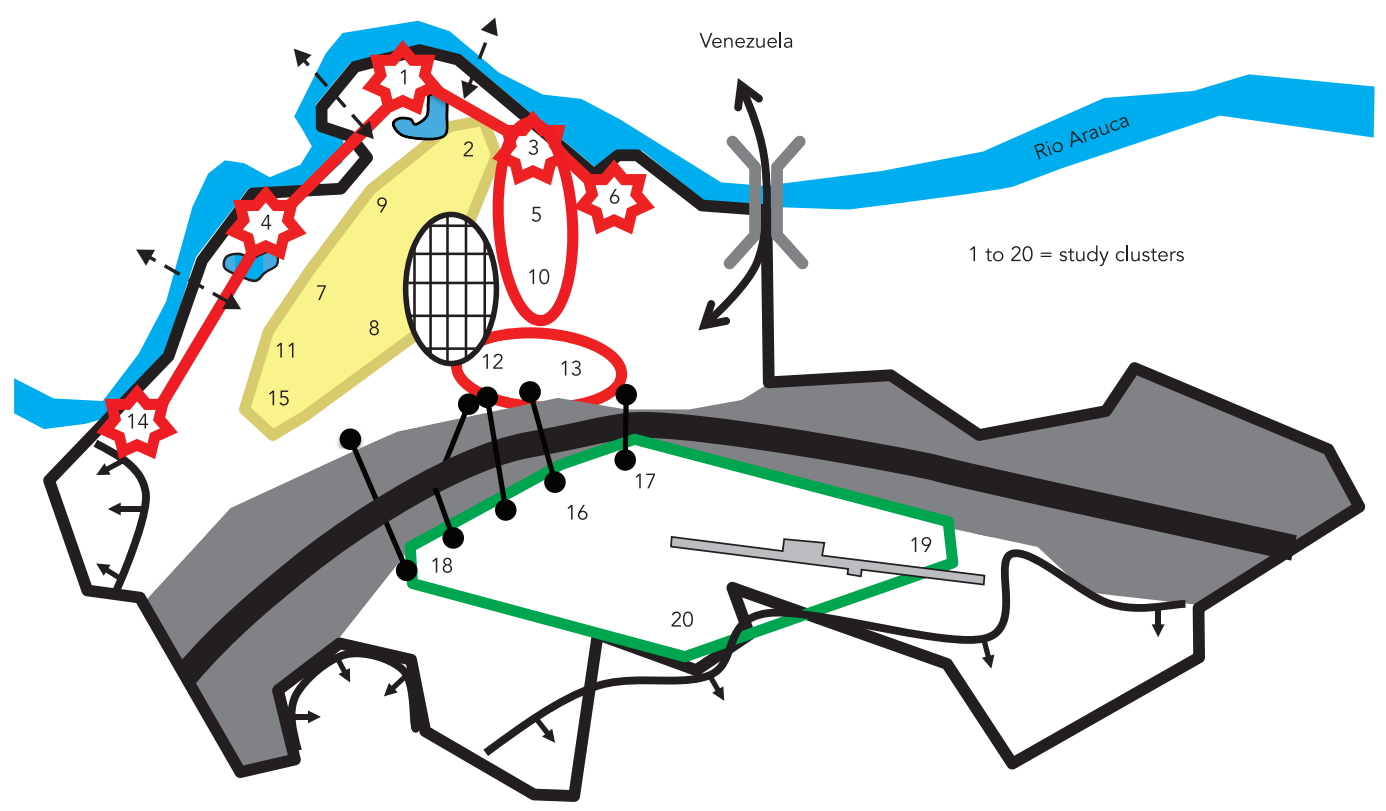

Formal border,
highway
$\begin{aligned} & \text { Informal border, } \\ & \text { Río Arauca } \\ & \text { Roads over environmental } \\ & \text { protection area }\end{aligned}$

Peripheral corridor with high A. aegypti density:

- Predominance of subsidized healthcare coverage and very low and low socioeconomic strata

- Above-average temperature, proximity to bodies of water (lagoons, canals, and Río Arauca) and risk of flooding

- Predominantly very high and high household water storage rates, adult-stage vector control activities, and

perception of government as responsible for dengue prevention

- Informal border activity, comprehensive neighborhood upgrading, and urban expansion

Central zone with high A. aegypti density:

- High household water storage rates and medium and high recall of visits by vector control program in the previous year

Zone with heterogeneous conditions and mixed (high and low) A. aegypti density:

- This zone includes 6 clusters with mixed entomological indices and very diverse social and behavioral conditions

\section{Zone with heterogeneous conditions and low A. aegypti density indices:}

- High reporting of individual responsibility for dengue control and medium to low recall of visits by vector control

program in the previous year

- Heterogeneity in socioeconomic strata (very low, low, and medium-high), healthcare coverage, and household water storage

- Population located in scattered urban settlements and lower presence of the most vector-productive containers (water tanks)

\section{Environmental protection zone acting as a division in urban characteristics and population's mobility:}

- Central zone to the north with more consolidated and dense urbanization and with high mobility (commerce, border, labor activities)

- Southern zone consisting of isolated, scattered urban settlements with less mobility of the population 


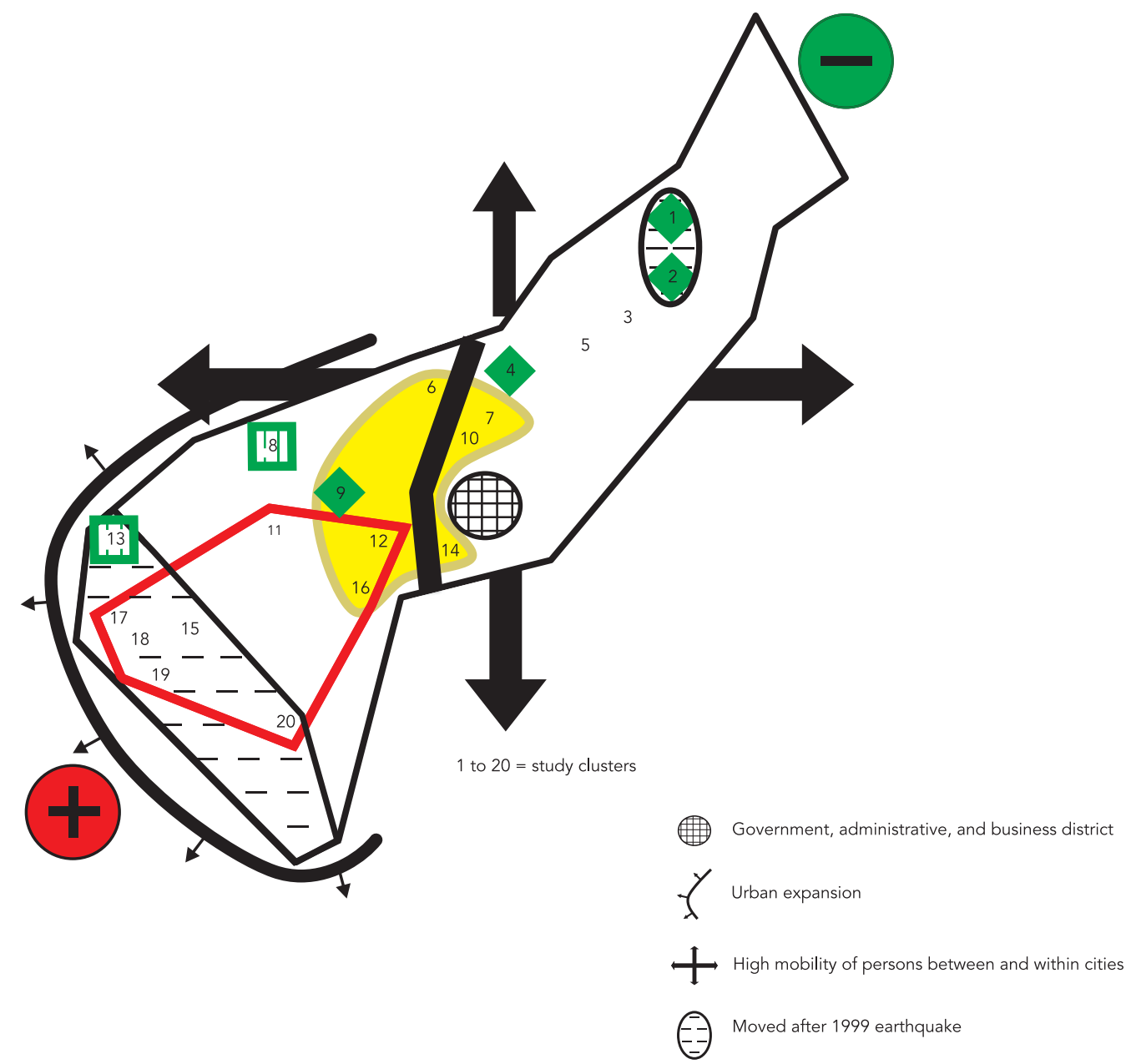

General division of the city: northeastern zone with lower $A$. aegypti density:

- Concentration of high socioeconomic strata, less mobility of persons, higher altitude (lower temperature), fewer water tanks in households, vector control activities against immature forms, and very low vector density

General division of the city: southeastern zone with higher $\mathbf{A}$. aegypti density:

- Concentration of medium and low socioeconomic strata, greater fragmentation of water drainage, zones of urban expansion and post-earthquake relocation, greater mobility of persons, lower altitude (higher temperature), vector control activities against adult forms, more household water tanks, and high vector density

Zone with concentration of high A. aegypti density:

- Predominance of very low and low socioeconomic strata

- High household water storage rates, high presence of the most productive containers for A. aegypti (water tanks), and low reporting of immature-stage vector control activities

11] Clusters in southwestern zone with low A. aegypti density:

- Medium and high recall of visits by vector control program and low presence of the most productive containers for the vector (water tanks)

Zone with heterogeneous and mixed (low to high) A. aegypti density:

- This zone includes 7 clusters with mixed entomological indices and very diverse social and behavioral conditions Coincides with a concentration of persons that still live in the same neighborhood as before the 1999 earthquake

Clusters with no pupae in households 
households. These clusters reported community actions against both the immature and adult stages of the mosquito.

Despite this diversity, these clusters reported above-average percentages (83\%) of people that identified dengue prevention as an individual responsibility, and showed medium and low recall of visits by the vector control program in the previous year. There were also few water tanks in these households when compared to the previously identified zones. Water tanks were the most productive containers in the city, with $92 \%$ of the pupae that were found.

\section{Vector density in Armenia and its} relationship to the territory's ecological and social structures

As in Arauca, Armenia was divided by zones, with a mix of ecological and social factors. The city showed a gradual change from the northeastern to the southwestern edges, reflected in the entomological indices and other study variables (Figure 3).

- General division of the city: northeastern zone with lower Aedes aegypti density

From the far northeast to the center of the city, we identified 5 clusters with low indices and another 3 where no pupae were found in the inspected households. Ecologically, the temperature drops as the altitude increases, reaching 1,600masl. This zone showed a mean temperature of $21.1^{\circ} \mathrm{C}$, almost five degrees lower than in the southwestern zone $\left(25.9^{\circ} \mathrm{C}\right)$.

The clusters also showed predominantly high-income households, less human mobility, and (according to Colombia's mandatory reporting system, SIVIGILA) a lower proportion of dengue cases in the first semester of 2013 when compared to the southwestern zone of the city. There were also clusters with fewer household water tanks $(42 \%$ to $71 \%)$ and the highest percentages (maximum $24 \%$ per cluster) of control measures against immature forms of the vector.

- General division of the city: southwestern zone with higher Aedes aegypti density

In the opposite direction, in the southwestern zone we identified 9 clusters that reported high vector indices, another 2 with low indices, and only 1 with no pupae found in the inspected households. From the center towards the southwest, there are medium to very low-income households, higher population density, higher mean temperature (reaching $25.9^{\circ} \mathrm{C}$ ), and more water drainage systems dividing the built-up area.

This side of the city has the neighborhoods that were rebuilt after the 1999 earthquake, which took a heavy physical and social toll. In Armenia, 21,810 households were completely destroyed or rendered useless 19 , which led to a complex reconstruction process 20,21 . As a result, the relocation projects were concentrated on the southwestern periphery of the city. Even more importantly, this post-earthquake resettlement caused a profound change in the social fabric.

Unlike the clusters in the northeastern zone, this zone reported higher percentages of positive containers (water tanks), ranging from $72 \%$ to $86 \%$. Some clusters reported control measures against adult mosquitos with percentages exceeding $85 \%$.

\section{- Zone with a concentration of high Aedes aegypti density}

Within the southwestern zone, we identified a general pattern with 8 clusters showing higher $A$. aegypti density (Figure 3), which coincides with very low, low, and middle-income strata. High household water storage rates (greater than 78\%) were also found in 6 of the 8 clusters. In addition, the highest percentage of vector control through community actions against immature forms was $9 \%$, the lowest for the city.

In the majority of the clusters in the city as a whole, more than $83 \%$ of the water in the inspected containers came from the aqueduct, but in 2 clusters in this group the proportion dropped to $65 \%$ and $69 \%$, meaning that around one-third of the containers had rainwater or a mixture of rainwater and aqueduct water. As mentioned previously, there were also more household water tanks, the containers that produce the most mosquitos.

Ecologically, there are more water drainage systems in this zone of the city, and the mean temperature is higher, as mentioned previously. Of the 8 clusters in this group, 5 are located on the outskirts of the city and are part of the reconstruction and resettlements zones that followed the earthquake in 1999.

\section{- Clusters in the southwestern zone with low Aedes aegypti density}

Figure 3 shows two clusters with the same general conditions as in the concentration zone discussed above, except with low vector density indices. In both clusters, nearly $60 \%$ of the people interviewed recalled visits from the vector control program in the previous year. Cluster 13 
(Figure 3) is one of the clusters with the lowest proportion of water tanks (below average, 69\%).

\section{- Zone with heterogeneous conditions and mixed Aedes aegypti density (low to high indices)}

Although one can identify overall patterns at both ends of the city, the central part contains 7 clusters with an important diversity of social conditions and vector behavior. This central strip has the highest percentages of people that currently live in the same neighborhood as before the earthquake in 1999 (from $40 \%$ to $62 \%$ per cluster). Of the 7 clusters mentioned, 3 showed lower vector density, 2 high density, and in another 2 pupae were not found in the inspected households. This strip also had vector control through community actions against both the immature and adult forms of A. aegypti (Figure 3).

\section{Discussion}

The study identified a relationship between the territory's structures and dynamics and vector density in both Arauca and Armenia, where interaction between ecological and social systems shapes specific zones with high and low $A$. aegypti density. Overall vector density was higher in Arauca than in Armenia, but both cities had groups of clusters with high vector activity. In most cases these high vector indices coincided with closely interrelated social and ecological structures that facilitate $A$. aegypti productivity: zones with no urban planning (urban expansion), settlements in flood-prone zones (Arauca), presence of low-income strata, high household water storage rates (not associated with the lack of running water from the aqueduct), more of the most vector-productive containers (water tanks), higher mean temperature than the rest of the city (an ecological factor that directly influences the vector capacity of A. aegypti 22), and control community actions targeted more to adult mosquitos than the immature forms.

Comparing the two types of zones with high entomological indices in Arauca (one peripheral and the other central), one assumes that there are ecological systems (bodies of water, temperature) and social systems (socioeconomic vulnerability, knowledge, practices) that may be structured differently but have the some outcome for vector density. For example, the central zone showed a higher institutional presence with more visits by the vector control program, plus less proximity to bodies of water and the river, which could lead to less inconvenience from mosquitos. As the clus- ters get farther from the river's course, the adultstage vector control measures decrease, which could impact vector prevention practices by the population.

In contrast, in the peripheral corridor the ecological conditions such as higher mean temperature, bodies of water, and flooded areas favor the proliferation of mosquitos (including A. aegypti). This can lead to dengue vector control activities, due more to the mosquito's annoying presence than to the actual risk of dengue transmission.

Armenia showed similar situations with a more complex interrelationship between the social and ecological systems that exhibit a tropism (a gradual change with an orientation) 9 that impacts the vector's behavior. Zones at lower altitudes are hotter and have more water drainage systems, lead to higher production of mosquitos (both A. aegypti and others) which in turn would cause greater discomfort for the inhabitants. In this sense, adult-stage mosquito control measures are not necessarily related to dengue prevention or vector prevention in this part of the city.

Importantly, both cities had low and high entomological indices in zones with similar social characteristics. This contributes to the discussion by not assigning excessive weight to socioeconomic vulnerability and insufficient infrastructure as sufficient determinants for understanding dengue vector density in urban settings. The literature on dengue in relationship to urbanization and living conditions with predominantly quantitative instruments is not conclusive 23,24 . Studies with a qualitative component have attempted to highlight the context's specificities to examine such relations 25,26 . Specifically, there are reports of higher A. aegypti indices in zones with formal urbanization as well as in vulnerable or deprived zones 27 , which emphasizes the complex interactions between social and ecological systems, beyond simply the degree of urbanization.

In Colombia, a relationship has been reported between unplanned urbanization, poverty, and lack of basic services and dengue transmission 1 . Nevertheless, in both cities in this study, household water storage was not related to the lack of running water from the aqueduct, since 96\% and 99\% of the interviewees in Arauca and Armenia, respectively, reported receiving running water from the aqueduct. Household water storage is more of a daily practice for home cleaning (93\%) and laundry (82\%) than for human consumption (9\%).

In Arauca, the southern zone of the city showed vulnerable socioeconomic conditions, but also structural elements that appear to 
have favored lower entomological indices. Less movement of people in and out of this zone and the urban discontinuity in this part of the city (scattered human settlements) may influence the density of $A$. aegypti, which is known to by a highly anthropophilic and endophagic species 28 . Another issue worth further exploration is the reason for the lower concentration of water tanks in these clusters. One characteristic they share and that can shed light on future studies is that these urban developments are more recent than the central part of the city, so they might have common elements in their design and construction that include fewer water tanks.

Both cities had groups of clusters without a clear trend in A. aegypti density, which may reflect the existence of borderline zones with diverse ecological and social conditions that need to be analyzed in greater detail with the help of statistical methods. These zones are located close to the center of the cities and display a diversity of social and ecological conditions. These are important for future studies, since they are characterized as meeting places and movements of persons that can play a central role in dengue transmission 25,29

In short, we emphasize the importance of indepth study of intra-urban zoning, referring to the genres de vie concept proposed by Max Sorre 30,31, establishing a horizontal dialogue (avoiding determinisms) between the territory's ecological and social structures, considering that geographic space is characterized by profound inequities and accelerated transformation. We contend that such approaches to territorial analyses should be expanded with the use of statistical methods.

Such studies should be continued, allowing the analysis of urban contexts in Colombia in relation to comprehensive analysis of vector density. They should also be complemented with more specific studies, using mathematic models to explore the influence of the urban landscape 32 , heterogeneous conditions on an intra-urban scale 33 , and the relationship between vector density and human density 29 in the distribution of the A. aegypti vector and dengue transmission in Colombian cities.

Likewise, an added value was found in the use of this methodology within an initiative that incorporates the ecosystem health approach. Briefly, it allows applying systemic thinking with the integration of diverse data sources on different scales, while performing its analysis from a transdisciplinary perspective with a fluid dialogue between different disciplines in search of a common objective. The chorematic method also has the potential to explore its use as a communications tool between diverse stakeholders in the decision-making process, thereby contributing to a common language between disciplines and sectors.

\section{Study strengths and limitations}

The chorematic method allowed a different use of data sources than that commonly adopted in this field (KAP surveys and entomological surveys). Nevertheless, it is possible to continue the use of these data sources for territorial analysis.

This study design (randomized clusters) is valid for comparing the vector's behavior between cities and has been used in various studies in Latin America 13 and Asia 14. However, in geographic terms there are parameters in the sample selection that can limit the territorial analysis presented here. By focusing the sampling on vector density for future evaluation of vector control and preventive interventions, the same number of clusters is proposed, ensuring comparability between cities, even with different population sizes. In Arauca, the clusters cover a greater land surface (214.4 hectares) than in Armenia, since it is a horizontal city (with mostly one-story households and larger premises), while in Armenia the area covered was 140.7 hectares, as a more dense and vertical city. There was also an important difference in the cities' urban area: in Arauca, the clusters covered an important share of the urban area, while in Armenia the clusters were much farther from each other and thus potentially hindering assessment of the territory.

Random selection of clusters allows the inclusion of areas from the entire city, but this does not necessarily mean that there is internal homogeneity in the clusters, which can be situated in borderline or transitions zones in terms of social and ecological conditions. Random selection also assumes that the urban space is homogeneous, overlooking that each city's social and ecological conditions are manifested in different proportions. It is necessary to find options that complement the advantages of traditional sampling to evaluate vector density, giving greater emphasis to territorial analysis, established as an intersection in cross-disciplinary exercises. In this sense, health geography provides proposals for the development of sampling 34 that can be considered for future studies.

\section{Conclusions}

Territorial analysis contributes to a more comprehensive understanding of the A. aegypti vector, thus emerging as a meeting place for crossdisciplinary exercises that strengthen studies 
with an ecosystem approach. This type of analysis can thus contribute to the development of more specific quantitative analyses, maintaining coherence with the contexts to which they are applied.

\section{Resumo}

Foi realizada uma análise territorial da densidade do Aedes aegypti em duas cidades da Colômbia, desde um enfoque ecossistêmico e da coremática. Com base em informação entomológica e comportamental (por conglomerados) e informação do contexto urbano, foi indagada a relação de estruturas dinâmicas do território com a densidade vetorial. Foram apresentados os resultados com modelos gráficos (coremática). Identificou-se maior densidade vetorial em Arauca do que na Armênia. Maiores densidades foram relacionadas à urbanização não planejada, zonas de alagamento, estratos socioeconômicos baixos, tanques baixos (reservatórios), maior temperatura e relatório de ações contra os mosquitos adultos. Zonas de densidades baixas coincidiram com diversas condições socioeconômicas, ecológicas e comportamentais. Foi encontrada uma relação das estruturas e dinâmicas do território com a densidade vetorial para Arauca e Armênia, onde a interação entre sistemas ecológicos e sociais configura zonas particulares de alta e baixa densidades de A. aegypti.

Aedes; Dengue; Geografia Médica; Zonas Urbanas; Condições Sociais
The chorematic method thus proved to be an appropriate tool for cross-disciplinary studies with an ecosystem approach for representing, describing, and analyzing the territorial dimension of the dengue vector Aedes aegypti, distinguishing urban scenarios in relation to its density.

\section{Contributors}

M. Fuentes-Vallejo, D. R. Higuera-Mendieta, and J. Quintero contributed to the study design and development, data collection and analysis, and writing and revision of the content. T. García-Betancourt, L. A. Alcalá-Espinosa, and D. García-Sanchez contributed to the study development, data collection, and writing and revision of the content. D. A. Munévar-Cagigas, H. L. Brochero, and C. González-Uribe contributed to the study development and writing and revision of the content.

\section{Acknowledgments}

The authors wish to thank the Arauca Special Health Administrative Unit (UAESA), the Armenia Health Secretariat, and the field staff that collaborated in the data collection in the two cities. Also to Simon Tomasi for his support during the fieldwork. 


\section{References}

1. Padilla JC, Rojas DP, Sáenz-Gómez R. Dengue en Colombia: epidemiología de la reemergencia a la hiperendemia. Bogotá: Guías de Impresión; 2012.

2. Powell JR, Tabachnick WJ. History of domestication and spread of Aedes aegypti: a review. Mem Inst Oswaldo Cruz 2013; 108 Suppl:11-7.

3. Charron DF, editor. Ecohealth research in practice: innovative applications of an ecosystem approach to health. Ottawa: Springer/International Development Research Centre; 2012.

4. Organización Panamericana de la Salud. Enfoques ecosistémicos en salud: perspectivas para su adopción en Brasil y los países de América Latina. Brasília: Organización Panamericana de la Salud; 2009.

5. Ministerio de Salud y Protección Social. Estrategia de gestión integrada para la promoción, prevención y control de las enfermedades transmitidas por vectores en Colombia, 2012-2021. Bogotá: Ministerio de Salud y Protección Social; 2013.

6. Alirol E, Getaz L, Stoll B, Chappuis F, Loutan L. Urbanisation and infectious diseases in a globalised world. Lancet Infect Dis 2011; 11:131-41.

7. Santos M. La naturaleza del espacio: técnica y tiempo. Razón y emoción. Barcelona: Ariel; 2000.

8. Montañez G, Carrizosa J, Suárez N, Delgado O, Lucio JA. Espacio y territorios: razón, pasión e imaginarios. Bogotá: UNIBIBLOS; 2001.

9. García J. La coremática y la nueva geografía regional francesa. Ería: Revista Cuatrimestral de Geografía 1998; 45:5-36.

10. Portugal J. Modelos gráficos y coremas: representación de la información territorial en sus componentes estructurales básicos. Lurralde: Investigación y Espacio 1996; 19:235-53.

11. Instituto Geográfico Agustin Codazzi. Atlas de Colombia. Bogotá: Instituto Geográfico Agustín Codazzi; 2002.

12. Ingeominas. Proyecto Compilación y Levantamiento de la Información Geomecánica. Características geomorfológicas del departamento del Quindío. Bogotá: Ingeominas; 2005.

13. Quintero J, Brochero H, Manrique-Saide P, Barrera-Pérez M, Basso C, Romero S, et al. Ecological, biological and social dimensions of dengue vector breeding in five urban settings of Latin America: a multi-country study. BMC Infect Dis 2014; 14:38.

14. Arunachalam N, Tana S, Espino F, Kittayapong P, Abeyewickreme W, Wai KT, et al. Eco-bio-social determinants of dengue vector breeding: a multicountry study in urban and periurban Asia. Bull World Health Organ 2010; 88:173-84.

15. Focks DA. A review of entomological sampling methods and indicators for dengue vectors. Geneva: World Health Organization; 2003.

16. Brunet R. La carte-modèle et les chorèmes. Mappemonde $1986 ; 4: 2-6$

17. Deler JD. Estructuras y dinámicas del espacio Colombiano. Cuadernos Geográficos 2001; X:165-80.

18. Catão RC. Dengue no Brasil: abordagem geográfica na escala nacional. São Paulo: Cultura Acadêmica; 2012.
19. Programa de las Naciones Unidas para el Desarrollo; Comisión Económica para América Latina y el Caribe. El terremoto de enero de 1999 en Colombia: impacto socioeconómico del desastre en la zona del Eje Cafetero. México DF: Programa de las Naciones Unidas para el Desarrollo; Comisión Económica para América Latina y el Caribe; 1999.

20. Londoño PA, Cardozo A, Zuluaga JA. Reasentamiento y borde. Armenia: Universidad Nacional de Colombia/Gerencia Transversal Armenia; 2002. (Enfoques de la Reconstrucción, 3).

21. González JI. El Forec como "modelo" de intervención del Estado. Armenia: Universidad Nacional de Colombia/Gerencia Transversal Armenia; 2003. (Enfoques de la Reconstrucción, 6).

22. Maciel-de-Freitas R. A review on the ecological determinants of Aedes aegypti (Diptera: Culicidae) vectorial capacity. Oecologia Australis 2010; 14:726-36.

23. Flauzino RF, Souza-Santos R, Barcelllos C, Gracie R, Magalhães MA, Oliveira RM. Spatial heterogeneity of dengue fever in local studies, City of Niterói, Southeastern Brazil. Rev Saúde Pública 2009; 43:1035-43.

24. Costa JV, Donalisio MR, Silveira LVA. Spatial distribution of dengue incidence and socio-environmental conditions in Campinas, São Paulo State, Brazil, 2007. Cad Saúde Pública 2013; 29:1522-32.

25. Donnat M, Gozalvez-Kreuzer B, Roca Y. La dynamique de la dengue à Santa Cruz de la Sierra (Bolivie) entre paysages à risques et mobilités: appréciation des inégalités et gestion du risque. Espace Popul Soc 2011; (1):34-46.

26. San Pedro A, Souza-Santos R, Sabroza PC, Oliveira RM. Condições particulares de produção e reprodução da dengue em nível local: estudo de Itaipu, Região Oceânica de Niterói, Rio de Janeiro, Brasil. Cad Saúde Pública 2009; 25:1937-46.

27. Maciel-de-Freitas R, MarquesW, Peres RC, Cunha SP, Oliveira RL. Variation in Aedes aegypti (Diptera: Culicidae) container productivity in a slum and a suburban district of Rio de Janeiro during dry and wet seasons. Mem Inst Oswaldo Cruz 2007; 102:489-96.

28. Marquetti MC. Aspectos bioecológicos de importancia para el control de Aedes aegypti y otros culícidos en el ecosistema urbano. Ciudad de La Habana: Instituto de Medicina Tropical Pedro Kourí; 2006.

29. Padmanabha H, Durham D, Correa F, Diuk-Wasser M, Galvani A. The interactive roles of Aedes aegypti super-production and human density in dengue transmission. PLoS Negl Trop Dis 2012; 6:e1799.

30. Ferreira MU. Epidemiologia e geografia: o complexo patogênico de Max Sorre. Cad Saúde Pública $1991 ; 7: 301-9$

31. Czeresnia D, Ribeiro AM. O conceito de espaço em epidemiologia: uma interpretação histórica e epistemológica. Cad Saúde Pública 2000; 16:595-617. 
32. Hemme RR, Thomas CL, Chadee DD, Severson DW. Influence of urban landscapes on population dynamics in a short-distance migrant mosquito: evidence for the dengue vector Aedes aegypti. PLoS Negl Trop Dis 2010; 4:e634.

33. Favier C, Schmit D, Müller-Graf CDM, Cazelles B, Degallier N, Mondet B, et al. Influence of spatial heterogeneity on an emerging infectious disease: the case of dengue epidemics. Proc Biol Sci 2005; 272:1171-7.
34. Vallée J, Souris M, Fournet F, Bochaton A, Mobillion V, Peyronnie K, et al. Sampling in health geography: reconciling geographical objectives and probabilistic methods. An example of a health survey in Vientiane (Lao PDR). Emerg Themes Epidemiol 2007; 4:6.

Submitted on 08/Apr/2014

Final version resubmitted on 01/Sep/2014

Approved on 15/Sep/2014 